\title{
Ground spider assemblages (Araneae: Gnaphosidae) along an urban-rural gradient in the city of Heraklion, Greece
}

\author{
Dimitris KALTSAS ${ }^{1 *}$, ElenI PANAYIOTOU ${ }^{1,2 * * * *}$, MARIA CHATZAKI ${ }^{3}$ and Moysis MYLONAS ${ }^{1,2}$ \\ ${ }^{1}$ Natural History Museum of Crete, University of Crete, Knossos Av., P.O. Box 2208, 71409 Heraklion, Crete, Greece; \\ e-mail: dimitris@nhmc.uoc.gr \\ ${ }^{2}$ Department of Biology, University of Crete, Vassilika Vouton, P.O. Box 2208, 71409 Heraklion, Crete, Greece; \\ e-mails: elen.panayiotou@gmail.com; mylonas@nhmc.uoc.gr \\ ${ }^{3}$ Department of Molecular Biology and Genetics, Democritus University of Thrace, Dragana, 68100 Alexandroupolis, Greece; \\ e-mail: maria.chatzaki@gmail.com
}

Key words. Gnaphosidae, ground spiders, urbanization, urban-rural gradient, Crete, Greece

\begin{abstract}
The responses of gnaphosid spiders to an urbanization gradient (urban-suburban-rural areas) were studied using pitfall traps in and near the city of Heraklion, in Crete, Greece, from October 2010 to October 2011. Our results indicate that richness and abundance of species of spiders decreased from the rural area to the center of the city, but not significantly so. Temporal beta diversity was significantly higher in urban areas, which indicates a high temporal variability in species composition of gnaphosid assemblages in the center of the city that takes the form of complementary rather than synchronized phenologies of co-occurring species, as expected in habitats degraded by high levels of disturbance. There was no specific pattern in the body size distribution of the gnaphosids along the urban-rural gradient, and thus the decrease in mean body size with increase in urbanization hypothesis was not supported by our results. However, the species composition recorded in urban areas was very different from that in suburban and rural areas. The percentage of individuals in the catches that were generalist species differed significantly along the gradient. As generalist gnaphosid species made up $72.01 \%$ of the total caught in the center of the city, and only $9.53 \%$ and $2.07 \%$ in suburban and rural areas respectively, our results support the opportunistic species hypothesis. Our analyses indicate that Urozelotes rusticus, a well known synanthropic species recorded for the first time in Greece, is an indicator of high levels of urbanization in Heraklion.
\end{abstract}

\section{INTRODUCTION}

The accelerating rate in the increase in the human population and technological development has arguably had a major effect on all the other species and ecosystems on the planet (Collins et al., 2000). The greatest increase in urban development has occurred over the last few decades. Approximately 50\% of humans worldwide live in cities ( $80 \%$ in developed countries), whereas this percentage was only $30 \%$ fifty years ago. In total, 67 million humans move into cities each year and, according to estimates, five billion people will be city dwellers by 2030 , i.e. $60 \%$ of the estimated population (United Nations, 2007). As in other European areas, urbanization in Crete, the fifth largest island in the Mediterranean, increased rapidly after the $1920 \mathrm{~s}$, since when the human population on the island has doubled. While in 1971 in Crete $55.8 \%$ of the people lived in suburban and rural areas and $44.2 \%$ in urban areas, the percentages in 1991 were $46.2 \%$ and $53.8 \%$, respectively (Briassoulis, 2003). Moreover, the population on Crete increased by $32 \%$ from 1971 to 2001 , mainly due to a continuous influx of people into the island's capital city, Heraklion, the population of which increased by $22 \%$ from 2001 to 2011 .

\footnotetext{
* These authors contributed equally to this work.

** Corresponding author.
}

Urban ecosystems are defined as areas under profound human influence, characterized by high density of human habitation and industrial development (Niemelä, 1999; McIntyre et al., 2001). Urbanization refers to the formation of urban ecosystems, which leads to the modification of the original landscape and habitats (McDonnell \& Pickett, 1990) or even the loss of natural habitats (Miyashita et al., 1998; Gibbs \& Stanton, 2001). Urban areas are also characterized by higher temperatures $\left(\sim 2-3^{\circ} \mathrm{C}\right)$ than surrounding areas and a higher abundance of non native, invasive and generalist species (McDonnell \& Pickett, 1990; Niemelä, 1999), which replace the native flora and fauna (Kowarik, 1995; Blair, 1996) and are often absent in the centers of cities (Marzluff et al., 2001). The effect of urbanization generally is more marked in the core of a city, which is surrounded by areas of decreasing habitation and development with moderate or low disturbance levels (Dickinson, 1996). Urbanization is the primary cause of several forms of disturbance, such as the alteration and fragmentation of natural habitats, changes in temperature, moisture and edaphic conditions, as well as high levels of pollution (McDonnell \& Pickett, 1990; Niemelä, 1999). The study of the responses of ecosystem to anthropogenic disturbance in urban areas is important for the well-being of humans and nature (Nie- 
melä, 1999). For studying the ecological changes that occur in areas with different levels of urbanization, urban-suburban-rural gradients were defined, based on the density of buildings and human habitation (Klausnitzer \& Richter, 1983; McDonnell \& Pickett, 1990), which reflect the general global pattern of urban development (Niemelä, 2000).

The effect of disturbance, like urbanization, on biotic communities is a focal point of modern ecological research, especially that on the tolerance of species to competitive exclusion and habitat loss due to different disturbance regimes and stressors. According to the intermediate disturbance hypothesis (Connell, 1978), diversity is maximal at intermediate levels of disturbance, which are enough to prevent competitive exclusion, but not high enough to cause species loss. As an alternative to the intermediate disturbance hypothesis, Gray (1989) proposed the increasing disturbance hypothesis, according to which diversity should monotonously decrease with increase in disturbance. According to a third hypothesis, under a high level of disturbance, overall diversity should decrease, opportunistic (generalist) species are predicted to become dominant (opportunistic species hypothesis) (Gray, 1989) and there is a decrease in the richness of species living in natural habitats (habitat specialist hypothesis) (Magura et al., 2008). In addition, when the level of disturbance is high, the mean size of the species present should be small (decreasing mean body size hypothesis), that is, small species should prevail in highly disturbed areas (e.g. city centers) (Gray, 1989; Blake et al., 1996; Ribera et al., 2001). Most studies on the occurrence of arthropods along urbanization gradients have affirmed the opportunistic species hypothesis and/or the increasing disturbance hypothesis (e.g. Niemelä et al., 2002; Magura et al., 2004; Elek \& Lövei, 2007; Vilisics et al., 2007).

Arthropods are ideal organisms for studying the effects of urbanization, primarily because they are directly affected by pollution, drainage and habitat loss (Pyle et al., 1981). Furthermore, arthropods respond quickly to anthropogenic disturbance because they have short generation times (McIntyre, 2000). In 1998 the Globenet research program on the effect of urbanization on biodiversity, focusing on ground beetles (Carabidae), was initiated (Niemelä et al., 2000). Most studies on the effect of urbanization on arthropods are on carabid beetles and butterflies with fewer on ants, bees, moths and flies (McKinney, 2008 and references therein). Though spiders are dominant components of the arthropod predatory guild (Wise, 1993) and have proved to be good bioindicators of anthropogenic disturbance (Maelfait \& Hendrickx, 1998), there are only a few studies on their response to urbanization (Fraser \& Frankie, 1986; Miyashita et al., 1998; Alaruikka et al., 2002; Cumming \& Wesołowska, 2004; Shochat et al., 2004; Magura et al., 2010). This study focuses on ground spiders (Araneae: Gnaphosidae), one of the largest spider families, which mainly includes fastmoving epigean nocturnal hunters, that are best collected using pitfall traps (Chatzaki, 2008). Currently Gnapho- sidae includes 2,134 species and 118 genera worldwide (Platnick, 2013) and is also one of the most diverse and dominant spider families in the Mediterranean region and Greece in particular (Chatzaki, 2003, 2008). More importantly, gnaphosids are known to respond to anthropogenic disturbance in the eastern Mediterranean (Kaltsas et al., 2012a).

Despite the growing interest in urban ecology, especially during the last decade, most of the studies were carried out in Northern Europe, North America and Asia (Niemelä \& Kotze, 2009), and there is only one relevant study for the Mediterranean region (Stefanescu et al., 2004). Our study focuses on gnaphosid spider assemblages along an urban-rural gradient in the city of Heraklion, on Crete, Greece. Specifically, we addressed the following questions:

1. How does the richness and abundance of gnaphosids change along an urban-rural gradient?

2. Does the structure of the assemblages along the gradient change (e.g. in terms of the presence or dominance of generalist/non-native species)?

3. Does the body size distribution change along the gradient?

4. Do the results support any indicator species of urbanization stress in Heraklion city?

\section{MATERIAL AND METHODS}

\section{Study area}

Heraklion is the largest city on Crete and the fourth largest in Greece (173,993 inhabitants in 2011). Urban habitats in Heraklion are characterized by the presence of introduced species of plants, such as the roadside Hirschefeldia incana and Conyza albida, the cliff endemic Petromarula pinnata and the Chinese tree Ailanthus altissima, which is dominant at the archaeological site of Knossos. The city flower of Heraklion is Hyoscyamus aureus, which is frequent in the Venetian city walls, its sole locality in Europe (Vogiatzakis \& Rackham, 2008). Rapid development of tourism over the last 55 years led to an expansion of the city to the west (Ammoudara province) and less in the east. The vegetation in the center of Heraklion consists mainly of non-native herbaceous species. Although most of the center of Heraklion is covered by buildings and roads, there are a few green areas, such as along the Venetian city walls and south of the city port.

We conducted our study in three types of habitat that represent rural, suburban and urban areas, as proposed in the Globenet protocol (Niemelä et al., 2000). We chose two axes of study: one from west to east and another from north to south, to cover the surrounding areas of Heraklion to the east, west and south of the city. Three sites were selected along each axis, representing the three levels of urbanization (nine sites in total). The selection of sites was made on the basis of the similarity of vegetation (Granchamp et al., 2000) and the percentage of built-up area in the vicinity of the sites (Ishitani et al., 2003), based on satellite photographs of the Prefecture of Heraklion. All urban habitats, characterized by the dominance of nonnative herbaceous vegetation, were located in the west (U1), the south (U2) and the east (U3) part of the city center. The suburban sites were dominated by indigenous herbaceous vegetation and Nerium oleander. The sites were situated at the western end of Ammoudara district (S1), SW of the city near the road to Moires (S2), and at the eastern end, approximately $2 \mathrm{~km} \mathrm{NW}$ of the city's industrial area (S3). Rural sites were located near the 


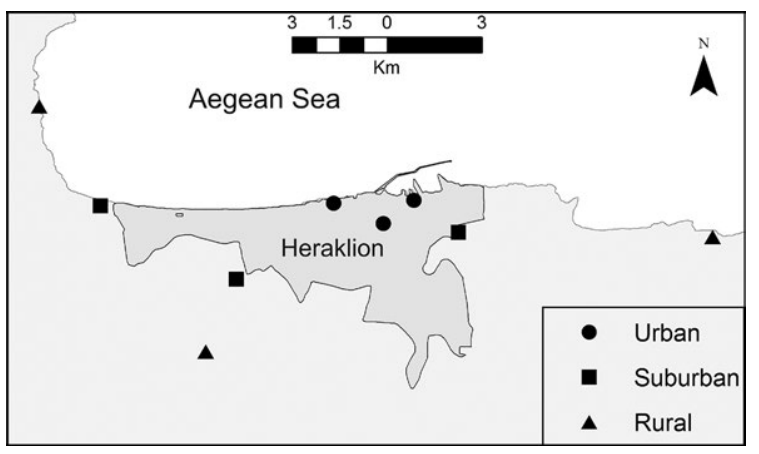

Fig. 1. Map of the area studied showing location of the sites sampled in and near Heraklion (grey area). U - urban sites; S suburban sites; R - rural sites. Neighbour urban development: U1 - sports centre, dense buildings, parking; U2 - dense buildings, parking; U3 - port, roads, dense buildings; S1 - hotels, electricity generating station; S2 - hotels, electricity generating station; S3 - industrial area, roads, houses; R1-R3 - road.

Palaiokastro bridge (national road to Rethymnon) (R1), $2.5 \mathrm{~km}$ SW of S2 (R2), and $1 \mathrm{~km}$ west of Kokkini Chani, near the road to Agios Nikolaos (R3). Vegetation at the rural sites was typical phrygana, dominated by Sarcopoterium spinosum, Thymbra capitata and Genista acanthoclada. The urban-rural gradient extended over $10.2 \mathrm{~km}$ from the city center to the west, $9.2 \mathrm{~km}$ to the east and $6.2 \mathrm{~km}$ to the south (Fig. 1).

\section{Sampling design}

We set 10 pitfall traps at each site, approximately $10 \mathrm{~m}$ apart along transects. Pitfall traps consisted of plastic containers, 12 $\mathrm{cm}$ tall and $9.5 \mathrm{~cm}$ in diameter at the top, containing propylene glycol as a preservative, which were set with the top of the trap flush with the surface of the ground. A total of 90 traps operated for a whole year, from October 2010 to October 2011 (3 areas $\times$ 3 sites $\times 10$ traps). Specimens were collected monthly (12 samples in total). Samples were sorted and all adult Gnaphosidae were identified to species. Nomenclature follows Platnick (2013) and the taxonomic additions that were subsequently published. The material is deposited in the Araneae collection of the Natural History Museum of the University of Crete.

\section{Statistical analyses}

The structural differences in the gnaphosid assemblages along the urbanization gradient were determined using non-metric multidimensional scaling (NMDS). Common and rare species were equally weighted by square root transformation of the data. NMDS was done using PAST 2.15 (Hammer et al., 2001).

We tested for differences in gnaphosid species richness, diversity, abundance and the percentage of individuals of generalist (opportunistic) gnaphosid species in the total captures along the three urbanization gradients. Diversity was measured using the Shannon diversity index:

$$
H^{\prime}=-\sum_{i} \frac{n_{i}}{n} \ln \frac{n_{i}}{n}
$$

where $n_{i}$ is the number of individuals of taxon $i$, and $n$ is the total number of individuals in a community at a given site. We also calculated the temporal beta diversity $(\beta t)$, measured as the temporal change in assemblage structure. The complementarity index of Colwell \& Coddington (1994) was applied:

$$
C_{j k}=\frac{S_{j}+S_{k}-2 V_{j k}}{S_{j}+S_{k}-V_{j k}} * 100
$$

where $S_{j}$ is the number of species captured in sampling period $j$, $S_{k}$ the number of species captured in consecutive sampling period $k(k=j+1)$ and $V_{j k}$ the species captured in both periods $j$

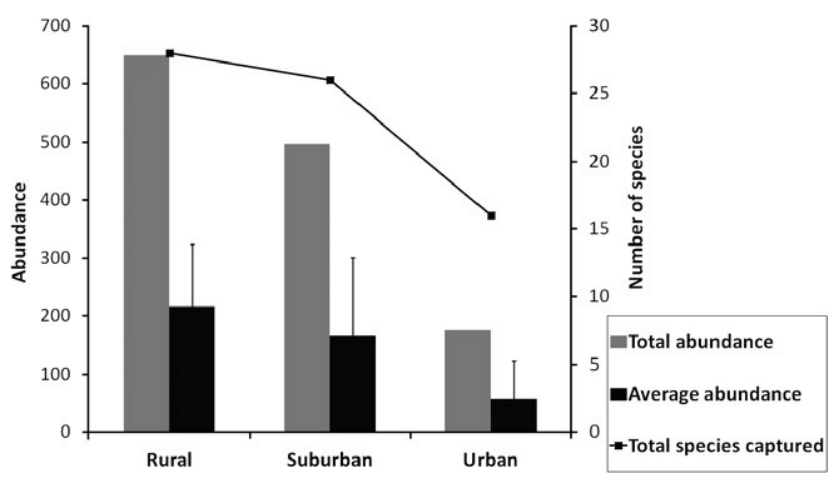

Fig. 2. Total and average species richness and abundance recorded along the urban-suburban-rural gradient.

and $k . C_{j k}$ was calculated for each sampling period, i.e. one month, and $\beta t$ for each gnaphosid assemblage is the average value (Zamora et al., 2007). The Shapiro-Wilk test showed that all variables were normally distributed. Thus, we applied one-way analysis of variance (ANOVA), pooling catches of individual traps for each study plot. Post-hoc analysis was performed using Tukey's test. Pair wise correlations among variables were calculated using Pearson's correlation coefficient, $r_{s}$. ANOVA was performed using PAST 2.15 (Hammer et al. 2001).

Body size inequality within gnaphosid assemblages was quantified using the Lorenz asymmetry coefficient $S$, as proposed by Damgaard \& Wiener (2000):

where

$$
S=\frac{m+\delta}{n}+\frac{L_{m}+\delta x_{m+1}^{\prime}}{L_{n}}
$$

$$
\delta=\frac{\bar{x}-x_{m}^{\prime}}{x_{m+1}^{\prime}-x_{m}^{\prime}}
$$

$\bar{x}$ is the mean body size of individuals in an assemblage, $m$ is the number of individuals with a body size smaller than $\bar{x}, L_{m}$ is the sum of body sizes of individuals smaller than $\bar{x}$, and $L_{n}$ is the cumulative body size of all $n$ individuals in an assemblage. When $S=1$, the Lorenz curve of the assemblage is symmetrical (perfect equality), while $S>1$ indicates that most of the inequality within the assemblage is due to the smallest individuals, and $S<1$ indicates the predominance of large individuals in the assemblage. The body size metric chosen was body length measured from the clypeus to the distal end of the abdomen, before the spinnerets.

Urbanization level was set as the grouping variable in the Indicator Species Analysis, which combines information on the concentration of the abundance of species in a particular group and the faithfulness of occurrence of a species in a particular group (Dufrêne \& Legendre, 1997). We excluded all species of which less than 20 individuals were caught. The Indicator Value index (IndVal) was computed for each species in each urbanization gradient and was tested for statistical significance by comparing it with the average of 4,999 permutations in PC-ORD 6.04 (McCune \& Mefford, 2011). The maximum value of IndVal is 100 and is recorded when all individuals of a species are solely captured at all sites of one specific factor class.

\section{RESULTS}

A total of 1,322 gnaphosid individuals belonging to 38 species and 20 genera were identified (Appendix 1). Most of the individuals were collected at rural (650 individuals, $49.2 \%$ of the total) and suburban sites (497 individuals, $37.6 \%$ of the total). Only 175 ground spiders were col- 
TABLE 1. One-way ANOVA results showing statistical differences in species richness, abundance, diversity (Shannon $H^{\prime}$ and temporal diversity, $\beta t$ ) and $\%$ abundance of generalist species of gnaphosids along a gradient of urbanization in Heraklion. The significant differences between different areas along the gradient $(\mathrm{p}<0.05)$ (Tukey test) are shown in the last column. $\mathrm{R}-$ rural; $\mathrm{S}-$ suburban; U - urban.

\begin{tabular}{lcccc}
\hline Dependent variable & MS & F & p & Tukey test \\
\hline Species richness & 31 & 1.01 & 0.419 & \\
Abundance & 19595.4 & 1.678 & 0.264 & \\
Shannon $H^{\prime}$ & 0.138 & 0.68 & 0.542 & \\
$\beta t$ & 433.15 & 13 & 0.007 & $\mathrm{U}>\mathrm{S}>\mathrm{R}$ \\
$\%$ abundance of generalist species & 0.375 & 10.42 & 0.011 & $\mathrm{U}>\mathrm{R}$ \\
\hline
\end{tabular}

lected in the city center (13.2\% of the total) (Fig. 2$)$. The total and average species richness and abundance were maximal in rural, minimal in urban and intermediate in suburban areas. In total, we identified 28 species in rural, 26 in suburban and only 16 gnaphosid species were collected in urban areas (Fig. 2). The average abundance of ground spiders recorded in urban areas was 2.84 and 3.71 times less than in suburban and rural areas, respectively. However, one-way ANOVA showed that the differences in species richness, abundance and Shannon $H^{\prime}$ diversity index at the gradient level were not statistically significant (Table 1). This was mainly due to the low richness and abundance of gnaphosids at site S3 (Appendix 1).

Three species were collected at sites in areas of all three levels of urbanization (Anagraphis pallens, Trachyzelotes lyonneti, Zelotes scrutatus). Four of the species collected were Cretan endemics (Drassylus pumiloides, Leptopilos hadjissaranti, Zelotes daidalus, Z. helicoides) and seven generalist species with varying degrees of synanthropism (Drassodes lapidosus, D. serratichelis, Scotophaeus scutulatus, Trachyzelotes lyonneti, Urozelotes rusticus, Zelotes laetus, Z. nilicola). The most abundant species were Pterotricha lentiginosa (11.93\% of the total gnaphosid catch), Drassyllus praeficus $(9.22 \%)$ and Zelotes subterraneus $(8.83 \%)$, which were all absent from urban areas. Our findings include the first records of Urozelotes rusticus and Zelotes laetus for Greece and the first records of Aphantaulax cincta and Berinda aegilia for Crete. B. aegilia was only collected in the center of Heraklion (sites U1, U2). The compositional differences of urban gnaphosid assemblages compared with those of suburban and rural areas was revealed by the twodimensional NMDS ordination plot, which explained $69.5 \%$ of the variance in the distance matrix (Axis 1: $63.8 \%$ of variance, Axis 2: $5.7 \%$ of variance, stress = 0.15; Fig. 3). The only exception was the gnaphosid assemblage at site $\mathrm{S} 3$, which was isolated from the rural and the other suburban assemblages in the NMDS plot.

The percentage of individuals of opportunistic gnaphosid species in the total catches differed significantly along the urbanization gradient. The Tukey test showed that this was due to the high abundance of generalist ground spiders in the center of the city than in suburban and rural areas, which also differed statistically (Table 2). Indeed, the abundance of opportunistic species in urban areas was 8.86 and 2.58 times greater than in rural and suburban areas, respectively (Fig. 4). Generalist species made up $70.86 \%$ of the total captures in the center of the city, whereas the respective percentages in suburban and rural areas were $9.66 \%$ and $2.15 \%$. Specifically, all generalist species were most abundant in urban areas, except Trachyzelotes lyonneti, which was most common in suburban areas and Zelotes laetus, whose presence must be very sporadic on the whole island, since it was not found before in spite of extensive surveys in the past (see Chatzaki et al., 2002a, b, 2003) and only one specimen was found in the present study (Appendix 1).

The temporal beta diversity $(\beta t)$ of gnaphosid assemblages differed significantly along the gradient (one-way ANOVA: $F=13 ; p=0.007)$. The Tukey post-hoc test showed that this was due to the significantly higher values of $\beta t$ in urban $(77.89 \%$ in average) compared to suburban (59.75\%) and rural areas (55.17\%), which did not differ statistically. Moreover, $\beta t$ was independent of species richness (Spearman's $r_{s}=-0.326 ; \mathrm{p}=0.392$ ). Though the Shannon index $\left(H^{\prime}\right)$ of ground spider assemblages was lowest on average in urban areas (1.658), it did not differ significantly among the three gradients (one-way ANOVA: $\mathrm{F}=0.680 ; \mathrm{p}=0.542$ ).

Indicator Species Analysis resulted in significance only for one species, Urozelotes rusticus, in urban areas (Table

TABLE 2. Indicator analysis results (indicator values sensu Dufrêne \& Legendre, 1997 recorded for each of the species in the different areas). The level of significance is based on 4,999 permutations. IndVals $>50$ are included. $\mathrm{R}-$ rural; $\mathrm{S}$ - suburban, U - urban.

\begin{tabular}{lccc}
\hline Species & Area & Recorded IndVal & $\mathrm{p}$ \\
\hline Urozelotes rusticus & $\mathrm{U}$ & 98.8 & 0.033 \\
Zelotes tenuis & $\mathrm{R}+\mathrm{S}$ & 83.3 & 0.113 \\
Zelotes scrutatus & $\mathrm{R}+\mathrm{S}$ & 81.6 & 0.077 \\
Trachyzelotes lyonneti & $\mathrm{S}$ & 74.9 & 0.078 \\
Anagraphis pallens & $\mathrm{R}+\mathrm{S}$ & 73.4 & 0.176 \\
Nomisia excerpta & $\mathrm{U}$ & 70.7 & 0.282 \\
Callilepis cretica & $\mathrm{R}$ & 66.7 & 0.253 \\
Leptodrassus albidus & $\mathrm{R}+\mathrm{S}$ & 66.7 & 0.148 \\
Drassodes lutescens & $\mathrm{R}+\mathrm{S}$ & 66.7 & 0.163 \\
Haplodrassus creticus & $\mathrm{R}$ & 65.4 & 0.253 \\
Drassyllus praeficus & $\mathrm{S}$ & 57 & 0.243 \\
Pterotricha lentiginosa & $\mathrm{R}$ & 55.9 & 0.470 \\
Zelotes solstitialis & $\mathrm{S}$ & 55.7 & 0.243 \\
\hline
\end{tabular}




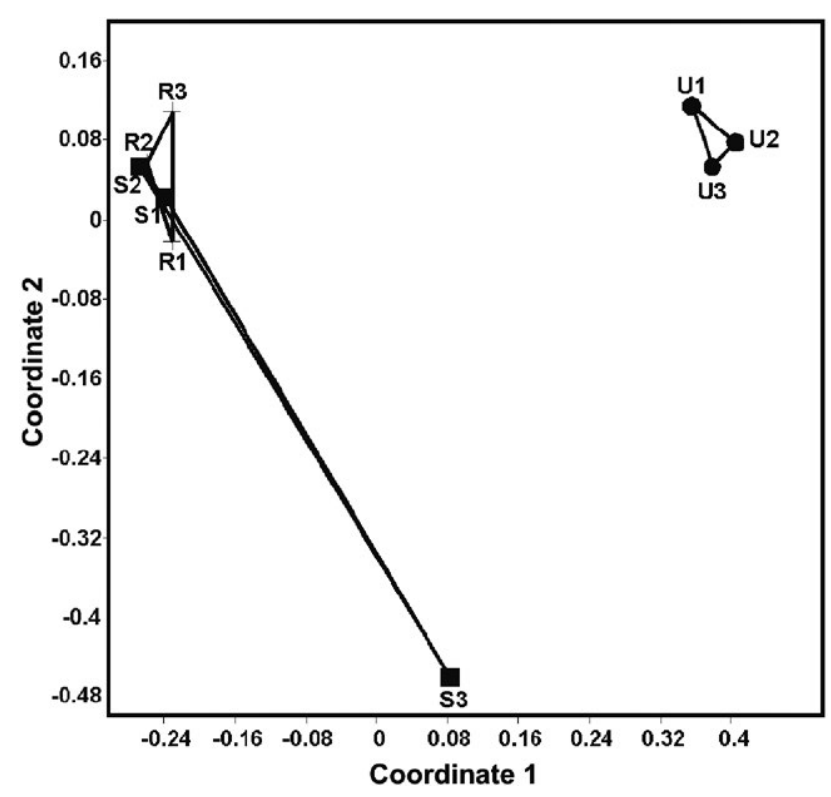

Fig. 3. NMDS ordination plot based on the Bray-Curtis dissimilarity matrix of the nine gnaphosid assemblages along the urbanization gradient.

2). U. rusticus was the dominant gnaphosid species in all urban areas, making up $48.94 \%$ of the total captures in urban areas, and only one individual of this species was collected outside the city center, i.e. at S1 (Appendix 1). The IndVals for $Z$. tenuis and $Z$. scrutatus were high for suburban and rural areas, but not significantly so (Table 2).

The Lorenz asymmetry coefficient $(S)$ did not reveal a specific pattern of gnaphosid body size distribution along the urban-rural gradient. Specifically, the results were highly variable in rural and suburban areas and characterized by the dominance of large-bodied individuals (R3, S1, S2) and small-bodied individuals (R1, R2, S3) (data not shown). Large bodied gnaphosids were also caught in all urban areas, where Urozelotes rusticus, one of the largest species collected in this study, was dominant. The average gnaphosid body size was similar at most sites (ca. 5-6 mm) and not correlated with $S$ (Spearman's $r_{s}=$ $-0.267 ; \mathrm{p}=0.463)$.

\section{DISCUSSION}

In accordance with the predictions of Gray (1989), our results indicate that urbanization has a negative effect on gnaphosid species richness and abundance. Both decreased in total and on average from rural to suburban areas and both were minimal in the center of Heraklion (Fig. 2), which conforms with the predictions of the increasing disturbance hypothesis (Gray, 1989). However this pattern was not supported statistically. The decrease in species in urban areas is directly connected with the impoverished flora, in terms of habitat loss (McKinney, 2002) and habitat fragmentation, which leads to isolated populations in such areas (Collins et al., 2000). Additionally, previous studies have shown that the carbon and nitrogen contents of urban soil are significantly lower than in rural soil, either due to the alteration of their

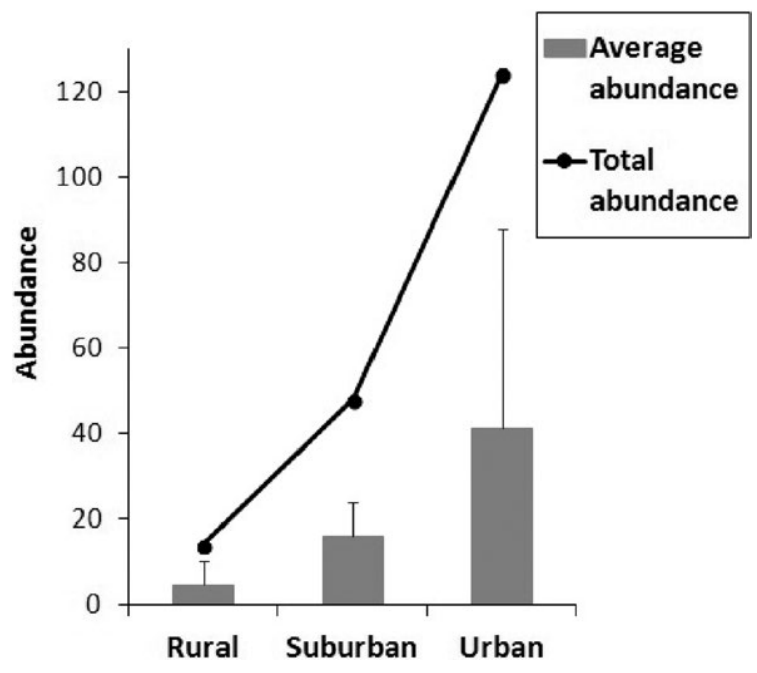

Fig. 4. Total and average abundances of generalist species of gnaphosids recorded along the urban-suburban-rural gradient.

cycling caused by chemical pollution (Lorenz \& Lal, 2009) or the dense impervious surfaces in urban areas (Raciti et al., 2012). The alteration in the levels of the two most important chemical elements in ecosystems affects the abundance of invertebrate predators, such as spiders (Hines et al., 2003).

The pattern of decreasing richness and abundance from rural to urban areas is affirmed by many studies on the ecology of plants and several animal taxa, especially invertebrates (McKinney, 2008 and references therein), including spiders (Magura et al., 2010; but Alaruikka et al., 2003). Though richness and abundance decreased from rural to urban areas in our study (Fig. 2), this was not confirmed statistically. This is similar to the results of Alaruikka et al. (2003), who ascribed this to the different small-scale habitat preferences of spiders. Though our statistical findings are similar (Table 2), the general pattern is different. This lack of statistical evidence of a decrease in richness/abundance from rural to urban areas was due to the very low richness and abundance of gnaphosids at site S3 (Appendix 1) near the industrial area of Heraklion and the fact that the richness and average abundance of gnaphosids did not vary much between suburban and rural areas (Fig. 2). Suburban habitats are considered to be transitional zones between natural and urban areas and are characterized by high environmental heterogeneity, because different habitats co-occur alongside one another (McKinney, 2002). Such habitat diversity has often led to a suburban peak in species richness of plants (Kowarik, 1995), butterflies (Blair, 1999; Konvicka \& Kadlec, 2011), mammals, birds, lizards, bumblebees and ants (McKinney, 2002 and references therein), which supports the predictions of the intermediate disturbance hypothesis, especially in cases of mild human effect of suburban sprawl (McKinney, 2002).

Apart from the quantitative comparisons, the composition of communities revealed very important clues about the effect of urbanization on gnaphosids. The structure of spider assemblages in the center of the city was significantly different from that in suburban and rural areas 
(Fig. 3), contrary to the findings of Alaruikka et al. (2003) and to a much greater extent those of Magura et al. (2010). The three most abundant species, Pterotricha lentiginosa, Drassyllus praeficus and Zelotes subterraneus, were not collected in the center of Heraklion. Considering that $P$. lentiginosa and $Z$. subterraneus are the two most common and most dominant gnaphosid species in natural habitats in Crete, and D. praeficus is among the five most abundant gnaphopsid species on the island (Chatzaki, 2003), their absence from urban sites is even more striking. The majority of gnaphosids captured in the centre of Heraklion were generalist species, unlike in the suburban and rural areas (Fig. 4). The fact that the percentage abundance of generalist gnaphosids in urban areas was 7.3 and 33 times higher than in suburban and rural areas, respectively, indicates that competitive displacement of native species of ground spiders might have occurred under increased urbanization, due to the establishment of similar but more opportunistic gnaphosid species in the center of Heraklion. Moreover, in all urban areas Urozelotes rusticus dominated making up almost half of the total catch in urban areas. Despite the fact that the gnaphosid fauna of natural ecosystems in Crete has been extensively studied, including that of most ecotope types and altitudinal ranges (Chatzaki, 2003), this is the first record of U. rusticus for Crete. U. rusticus is a well known cosmopolitan, synanthropic species, common in buildings, houses and gardens (Platnick \& Shahab, 1983). Our results highlight U. rusticus as an indicator species of high urbanization levels in Heraklion (Table 2) and provides further evidence of synanthropic character of this species (Platnick \& Murphy, 1984).

Our results support the opportunistic species hypothesis, as generalist (opportunistic) gnaphosid species were dominant in urban areas and their relative abundance decreased significantly in suburban and even more so in rural areas (Table 1). The opportunistic species hypothesis is also well supported for carabid assemblages (Niemelä et al., 2002; Magura et al., 2004; Elek \& Lövei, 2007) along urban-rural gradients. Wootton (1998) modelled the effects of disturbance on ecological communities and found that basal species in food webs conform to the intermediate disturbance hypothesis, whereas top consumers do not. Considering the fact that Carabidae and Gnaphosidae are both high level consumers, Wootton's results provide a plausible explanation for the support for the opportunistic species hypothesis in both carabid and gnaphosid communities. However, such generalizations should be treated cautiously. The diversity patterns along disturbance regimes depend on the nature and intensity of disturbance (Kaltsas et al., 2013). Emphasis should be given to the implications of mortality, non-equilibrium dynamics and spatial heterogeneity; the three fundamental components of disturbance. The fact that mortality, a major response of arthropods to habitat loss and pollution caused by urbanization (McIntyre, 2000), had the largest effect on the outcome of Wootton's (1998) models, further supports the relevance of the opportunistic species hypothesis in accounting for the differences in predator assemblages along urban-rural gradients.

Temporal beta diversity $(\beta t)$ of spider assemblages differed significantly along the three urbanization gradients. The average temporal change in community structure was significantly higher in urban than in suburban and rural assemblages, independent of local species richness. Such high values of temporal beta diversity are attributed to degraded habitats due to strong perturbation (Romanuk \& Kolasa, 2001) and are reported for carabids in overgrazed areas in the eastern Mediterranean, including Crete (Kaltsas et al., 2012b). Thus, the high $\beta t$ values recorded in urban areas in our study were a result of mutual temporal avoidance of co-occurring species in the form of complementing rather than synchronized phenologies, due to a high level of urbanization and the direct effects of consequent disturbance forms.

In contrast to the changes in the abundance and diversity of ground spiders along the urban-rural gradient, there did not appear to be any specific pattern in their body size distributions. Large spiders were dominant in most assemblages, except for three sites outside the center of the city (R1, R2, S3). In addition, the average body size of individuals did not differ among sites or urbanization gradients and thus do not support Gray's (1989) decreasing mean body size hypothesis along gradients of increasing disturbance. Nevertheless, the results for gnaphosids in areas under different grazing levels in east Mediterranean maquis support Gray's hypothesis (Kaltsas et al., 2012a). This discordance of results is mainly due to the dominance of relatively large generalist species in urban areas (like Urozelotes rusticus), which is not recorded by Kaltsas et al. (2012a). Apparently, the body size distributions of ground spiders depend on: (a) the nature of disturbance, the forms of which affect gnaphosid assemblages quite differently, and (b) specific habitat characteristics of the sites studied and their capacity to accommodate non indigenous species (hence for instance their proximity to a large harbour), thus resulting in dissimilar community compositions.

Overall, our results indicate that urbanization in Heraklion strongly affects assemblages of ground spiders and results in decreases in spider biodiversity and abundance. Indigenous species are replaced by generalist species in the assemblages in the center of Heraklion, which vary temporally in species composition. Like several previous studies on other arthropod groups, our work provides additional evidence that urbanization is a leading cause of decline in the diversity and abundance of indigenous arthropods (Davis, 1978).

ACKNOWLEDGEMENTS. We are indebted to S. Simaiakis, A. Nersessian and N. Tsirigotakis for their help with setting the pitfall traps and collecting specimens. We are also grateful to $\mathrm{M}$. Nikolakakis for designing the map and J. Dunlop for his linguistic comments.

\section{REFERENCES}

Alaruikka D., Kotze D.J., Matveinen K. \& Niemela J. 2002: Carabid beetle and spider assemblages along a forested urban- 
rural gradient in Southern Finland. - J. Insect Conserv. 6: 195-206.

BlaIR R.B. 1996: Land use and avian species diversity along an urban gradient. - Ecol. Appl. 6: 506-519.

BLAIR R.B. 1999: Birds and butterflies along an urban gradient: Surrogate taxa for assessing biodiversity? - Ecol. Appl. 9: 164-170.

Blake S., Foster G.N., Fisher E.J. \& Ligertwood G.L. 1996: Effects of management practices on the carabid faunas of newly established wildflower meadows in southern Scotland. - Ann. Zool. Fenn. 33: 139-147.

Briassoulis H. 2003: Crete: endowed by nature, privileged by geography, threated by tourism? - J. Sustain. Tour. 11: 97-115.

Chatzaki M. 2003: Ground Spiders of Crete (Araneae, Gnaphosidae): Taxonomy, Ecology and Biogeography. PhD Thesis, University of Crete, $452 \mathrm{pp}$. [in Greek].

Chatzaki M. 2008: A critical review of the spider family Gnaphosidae in Greece. In Makarov S.E. \& Dimitrijeviæ R.N. (eds): Advances in Arachnology and Developmental Biology. Papers Dedicated to Prof. Dr. Božidar Ćurčić. Inst. Zool., Belgrade; BAS, Sofia; Fac. Life Sci., Vienna; SASA, Belgrade \& UNESCO MAB Serbia, Vienna-Belgrade-Sofia, Monographs 12, pp. 355-374.

Chatzaki M., Thaler K. \& Mylonas M. 2002a: Ground spiders (Gnaphosidae, Araneae) of Crete (Greece). Taxonomy and distribution. I. - Rev. Suisse Zool. 109: 553-601.

Chatzaki M., Thaler K. \& Mylonas M. 2002b: Ground spiders (Gnaphosidae, Araneae) of Crete and adjacent areas of Greece. Taxonomy and distribution. II. - Rev. Suisse Zool. 109: 603-633.

Chatzaki M., Thaler K. \& Mylonas M. 2003: Ground spiders (Gnaphosidae, Araneae) from Crete and adjacent areas of Greece. Taxonomy and distribution. III: Zelotes and allied genera. - Rev. Suisse Zool. 110: 45-89.

Collins J.P., Kinzig A., Grimm N.-B., Fagan W.F., Hope D., Wu J. \& Borer W.T. 2000: A new urban ecology. - Am. Sci. 88: 416-425.

Colwell R.K. \& Coddington J.A. 1994: Estimating terrestrial biodiversity through extrapolation. - Phil. Trans. R. Soc. (B) 345: $101-118$.

ConNell J.H. 1978: Diversity in rain forests and coral reefs. Science 199: 1302-1310.

Cumming M.S. \& Wesolowska W. 2004: Habitat separation in a species-rich assemblage of jumping spiders (Araneae: Salticidae) in a suburban study site in Zimbabwe. $-J$. Zool. 262: $1-10$.

DAmgaARD C. \& Weiner J. 2000: Describing inequality in plant size or fecundity. - Ecology 81: 1139-1142.

DAvis B.N.K. 1978: Urbanisation and the diversity of insects. In Mound L.A. \& Waloff N. (eds): Diversity of Insect Faunas Blackwell, London, pp. 126-138.

DickINSON R.E. 1996: The process of urbanisation. In Darling F.F. \& Milton J.P. (eds): Future Environments of North America. Natural History Press, Garden City, NY, pp. 463-478.

DufrêNe M. \& Legendre P. 1997: Species assemblages and indicator species: the need for a flexible assymetrical approach. - Ecol. Monogr. 67: 345-366.

Elek Z. \& LöveI G.L. 2007: Patterns in ground beetle (Coleoptera: Carabidae) assemblages along an urbanisation gradient in Denmark. - Acta Oecol. 32: 104-111.

FraSER J.B. \& FranKIE G.W. 1986: An ecological comparison of spiders from urban and natural habitats in California. - Hilgardia 54: 1-24.
Gibis J.P. \& Stanton E.J. 2001: Habitat fragmentation and arthropod community change: carrion beetles, phoretic mites, and flies. - Ecol. Appl. 11: 79-85.

Grandchamp A.-C., Niemelä J. \& Kotze J. 2000: The effects of trampling on assemblages of ground beetles (Coleoptera, Carabidae) in urban forests in Helsinki, Finland. - Urban Ecosyst. 4: 321-332.

GRAY J.S. 1989: Effects of environmental stress on species rich assemblages. - Biol. J. Linn. Soc. 37: 19-32.

Hammer Ø., Harper D.A.T. \& Ryan P.D. 2001: PAST: Paleontological Statistics Software Package for Education and Data Analysis. Palaeontol. Electron. 4(1): $9 . \quad \mathrm{http}: / /$ palaeo-electronica.org/2001_1/past/issue1_01.htm, Accessed 28 June 2013.

Hines J., Megonigal J.P. \& Denno R.F. 2003: Nutrient subsidies to belowground microbes impact aboveground food web interactions. - Ecology 87: 1542-1555.

Ishitani M., Kotze D.J. \& Niemelä J. 2003: Changes in carabid beetle assemblages across an urban-rural gradient in Japan. Ecography 26: 481-489.

Kaltsas D., Panayiotou E., Trichas A., Chatzaki M. \& MYlonas M. 2012a: Co-occurrence patterns and shaping processes of assembly in beetle and spider communities in eastern Mediterranean maquis formations. - J. Biol. Res. (Thessaloniki) 18: 187-197.

Kaltsas D., Trichas A. \& Mylonas M. 2012b: Temporal organization patterns of epigean beetle communities (Coleoptera: Carabidae, Tenebrionidae) in different successional stages of eastern Mediterranean maquis. - J. Nat. Hist. 46: 495-515.

Kaltsas D., Trichas A., Kougioumoutzis K. \& Chatzaki M. 2013: Ground beetles respond to grazing at assemblage level, rather than species specifically: the case of Cretan shrublands. - J. Insect Conserv. 17: 681-697.

KLAusNitzer B. \& Richter K. 1983: Presence of an urban gradient demonstrated for carabid associations. - Oecologia 59: 79-82.

KonvicKa M. \& KADLEC T. 2011: How to increase the value of urban areas for butterfly conservation? A lesson from Prague nature reserves and parks. - Eur. J. Entomol. 108: 219-229.

KowARIK L. 1995: On the role of alien species in urban flora and vegetation. In Pysek P.K., Parch M., Rejmanek M. \& Wade P.M. (eds): Plant Invasions: General Aspects and Special Problems. SPB Academic, Amsterdam, pp. 85-103.

Lorenz K. \& LAL R. 2009: Biogeochemical C and N cycles in urban soils. - Environ. Int. 35: 1-8.

McCune B. \& MefFord M.J. 2011: PC-ORD. Multivariate Analysis of Ecological Data. Version 6.0. MjM Software, Gleneden Beach, Oregon, U.S.A.

McDonnell M.J. \& PicketT S.T.A. 1990: Ecosystem structure and function along urban-rural gradients: an unexploited opportunity for ecology. - Ecology 71: 1232-1237.

MCINTYRE N.E. 2000: Ecology of urban arthropods: A review and a call to action. - Ann. Entomol. Soc. Am. 93: 825-835.

McIntyre N.E., Rango J., Fagan W.F. \& Faeth S.H. 2001: Ground arthropod community structure in a heterogeneous urban environment. - Landsc. Urban Plan. 52: 257-274.

McKinNEY M.L. 2002: Urbanisation, Biodiversity, and Conservation. - Bioscience 52: 883-890.

McKINNEY M.L. 2008: Effects of urbanization on species richness: A review of plants and animals. - Urban Ecosyst. 11: 161-176.

Maelfait J.-P. \& Hendrickx F. 1998: Spiders as bio-indicators of anthropogenic stress in natural and semi-natural habitats in Flanders (Belgium): some recent developments. In Selden 
P.A. (ed.): Proceedings of the 17th European Colloquium of Arachnology, Edinburgh 1997. British Arachnological Society, Burnham Beeches, Bucks, pp. 293-300.

Magura T., Tóthmérész B. \& Molnár T. 2004: Changes in carabid beetle assemblages along an urbanisation gradient in the city of Debrecen, Hungary. - Landsc. Ecol. 19: 747-759.

Magura T., Tóthmérész B., Hornung E. \& Horváth R. 2008: Urbanisation and ground-dwelling invertebrates. In Wagner L.N. (ed.): Urbanisation: 21 st Century Issues and Challenges. Nova Science Publishers, New York, pp. 213-225.

Magura T., Horváth R. \& Tóthmérész B. 2010: Effects of urbanization on ground-dwelling spiders in forest patches, in Hungary. - Landsc. Ecol. 25: 621-629.

Marzluff J.M., Bowman R. \& Donnely R. 2001: A historical perspecrive on urban bird reserach: trends, terms, and approaches. In Marzluff J.M., Bowman R. \& Donnely R. (eds): Avian Ecology in an Urbanizing World. Kluwer Academic, Norwell, MA, pp. 1-18.

Miyashita T., Shinkai A. \& Chida T. 1998: The effects of forest fragmentation on web spider communities in urban areas. Biol. Conserv. 86: 357-364.

NIEMELÄ J. 1999: Is there a need for a theory of urban ecology? - Urban Ecosyst. 3: 57-65.

NIEMELÄ J. 2000: Biodiversity monitoring for decision-making. - Annal. Zool. Fenn. 37: 307-317.

Niemelä J. \& Kotze J. 2009: Carabid beetle assemblages along urban to rural gradients: A review. - Landsc. Urban Plann. 92: 65-71.

Niemelä J., Kotze J., Ashworth A., Brandmayr P., Desender K., New T., Penev L., Samways M. \& Spence J. 2000: The search for common impacts on biodiversity: A global network. - J. Insect Conserv. 4: 3-9.

Niemelä J., Kotze J.D., Venn S., Penev L., Stoyanov I., Spence J., Hartley D. \& Montes de Oca E. 2002: Carabid beetle assemblages (Coleoptera, Carabidae) across urban-rural gradients: an international comparison. - Landsc. Ecol. 17: 387-401.

Platnick N.I. 2013: The World Spider Catalog, Version 13.5. Online at http://research.amnh.org/iz/spiders/catalog. American Museum of Natural History.

Platnick N.I. \& MurPhy J.A. 1984: A revision of the spider genera Trachyzelotes and Urozelotes (Araneae, Gnaphosidae). - Am. Mus. Nov. 2792: 1-30.
Platnick N.I. \& Shadab M.U. 1983: A revision of the American spiders of the genus Zelotes (Araneae, Gnaphosidae). $-\mathrm{Br}$. Am. Mus. Nat. Hist. 174: 97-192.

Pyle R., Bentzien M. \& Opler P. 1981: Insect conservation. Annu. Rev. Entomol. 26: 233-258.

Raciti S.M., Hutyra L.R. \& Finzi A.C. 2012: Depleted soil carbon and nitrogen pools beneath impervious surfaces. Environ. Pollut. 164: 248-251.

Ribera I., Dolédec S., Downie I.S. \& Foster G.N. 2001: Effect of land disturbance and stress on species traits of ground beetle assemblages. - Ecology 82: 1112-1129.

RoManuK T.N. \& Kolasa J. 2001: Simplifying the complexity of temporal diversity dynamics: a differentiation approach. Ecoscience 8: 259-263.

Shochat E., Stefanov W.L., Whitehouse M.E.A. \& Faeth S.H. 2004: Urbanisation and spider diversity: influences of human modification of habitat structure and productivity. - Ecol. Appl. 14: 268-280.

Stefanescu C., Herrando S. \& Paramo F. 2004: Butterfly species richness in the north-west Mediterranean Basin: the role of natural and human-induced factors. $-J$. Biogeogr. 31: 905-915.

United Nations 2007: State of World Population 2007: Unleashing the Potential of Urban Growth. United Nations Population Fund., 99 pp.

Vilisics F., Elek Z., Lövei G.L. \& Hornung E. 2007: Composition of terrestrial isopod assemblages along an urbanisation gradient in Denmark. - Pedobiologia 51: 45-53.

Vogiatzakis I.N. \& Rackham O. 2008: Chapter 11: Crete. In Vogiatzakis I.N., Pungetti G. \& Mannion A. (eds): Mediterranean Island Landscapes: Natural and Cultural Approaches. Landscape Series Vol. 9. Springer, Dordrecht, pp. 245-270.

WISE D.H. 1993: Spiders in Ecological Webs. Cambridge University Press, New York, 328 pp.

WооттоN J.T. 1998: Effects of disturbance on species diversity: a multitrophic perspective. - Am. Nat. 152: 803-825.

Zamora J., Verdú J.R. \& Galante E. 2007: Species richness in Mediterranean agroecosystems: Spatial and temporal analysis for biodiversity conservation. - Biol. Conserv. 134: $113-121$.

Received April 25, 2013; revised and accepted August 19, 2013

APPENDix 1. The number of individuals of all the species trapped at each study site and in total. $\mathrm{R}-$ rural; $\mathrm{S}-\mathrm{suburban} ; \mathrm{U}-$ urban. ${ }^{*}$ - Cretan endemic species. ${ }^{+}$- generalist species.

\begin{tabular}{|c|c|c|c|c|c|c|c|c|c|c|}
\hline Species & $\mathrm{R} 1$ & $\mathrm{R} 2$ & R3 & S1 & S2 & S3 & U1 & $\mathrm{U} 2$ & U3 & Total \\
\hline Anagraphis pallens Simon, 1893 & 13 & 16 & 4 & 20 & 3 & & 2 & & 2 & 60 \\
\hline Aphantaulax cincta (L. Koch, 1866) & & & & 1 & & & 1 & & & 2 \\
\hline Berinda aegilia Chatzaki, 2002 & & & & & & & 1 & 1 & & 2 \\
\hline Callilepis cretica (Roewer, 1928) & 13 & 13 & & & & & & & & 26 \\
\hline Zelotes metellus Roewer, 1928 & & 1 & & 1 & & & & & & 2 \\
\hline Cesonia aspida Chatzaki, 2002 & & & 2 & & & & & & & 2 \\
\hline Drassodes lapidosus (Walckenaer, 1802) ${ }^{+}$ & & & 2 & & & & 7 & 1 & 1 & 11 \\
\hline Drassodes lutescens (C.L. Koch, 1839) & 7 & & 44 & 6 & & 6 & & & & 63 \\
\hline Drassodes serratichelis (Roewer, 1928) ${ }^{+}$ & & 1 & & & & & 15 & 2 & 1 & 19 \\
\hline Drassyllus praeficus (L. Koch, 1866) & & 18 & & 77 & 26 & & & & & 121 \\
\hline Drassyllus pumiloides Chatzaki, 2003* & & & & 2 & & & & & & 2 \\
\hline Haplodrassus creticus (Roewer, 1928) & 38 & & 16 & & 1 & & & & & 55 \\
\hline Leptodrassus albidus Simon, 1914 & 1 & 4 & & 35 & 3 & & & & & 43 \\
\hline
\end{tabular}


ApPendix 1 (continued).

\begin{tabular}{|c|c|c|c|c|c|c|c|c|c|c|}
\hline Species & $\mathrm{R} 1$ & $\mathrm{R} 2$ & $\mathrm{R} 3$ & S1 & S2 & S3 & U1 & $\mathrm{U} 2$ & U3 & Total \\
\hline Leptodrassus femineus (Simon, 1873) & 1 & & 2 & & & & & & & 3 \\
\hline Leptopilos hadjissaranti (Chatzaki, 2002)* & 5 & & & & & & & & & 5 \\
\hline Leptopilos pupa (Dalmas, 1919) & & & & 1 & 1 & & 1 & & 1 & 4 \\
\hline Micaria coarctata (Lucas, 1846) & & 15 & 2 & & & & 1 & & & 18 \\
\hline Micaria ignea (O. P.-Cambridge, 1872) & & & & 1 & & & 1 & & & 2 \\
\hline Nomisia excerpta (O. P.-Cambridge, 1872) & 3 & 7 & 6 & & & & 31 & 3 & 3 & 53 \\
\hline Nomisia ripariensis (O. P.-Cambridge, 1872) & & 3 & & 8 & 3 & & & & & 14 \\
\hline Poecilochroa senilis (O. P.-Cambridge, 1872) & & & 1 & & & & & & & 1 \\
\hline Pterotricha lentiginosa (C.L. Koch, 1837) & 18 & & 117 & & 26 & & & & & 161 \\
\hline Scotophaeus scutulatus (L. Koch, 1866) ${ }^{+}$ & & & & & & 2 & 3 & 4 & & 9 \\
\hline Setaphis carmeli (O. P.-Cambridge, 1872) & & 29 & & & 9 & & & & & 38 \\
\hline Synaphosus trichopus (Roewer, 1928) & & 4 & & & 5 & 1 & & & & 10 \\
\hline Trachyzelotes lyonneti (Audouin, 1826) ${ }^{+}$ & 1 & 10 & & 16 & 8 & 14 & & & 2 & 51 \\
\hline Trachyzelotes malkini Platnick \& Murphy, 1984 & 2 & & 3 & & & & & & & 5 \\
\hline Urozelotes rusticus (L. Koch, 1872) ${ }^{+}$ & & & & 1 & & & 65 & 7 & 10 & 83 \\
\hline Zelotes caucasius (L. Koch, 1866) & & 32 & 7 & 25 & 15 & & & & & 79 \\
\hline Zelotes daidalus Chatzaki, 2003* & & 2 & & & & & & & & 2 \\
\hline Zelotes helicoides Chatzaki, 2010* & & & & 13 & & 2 & & & 2 & 17 \\
\hline Zelotes laetus (O. P.-Cambridge, 1872) ${ }^{+}$ & & & & 3 & & & & & & 3 \\
\hline Zelotes nilicola (O. P.-Cambridge, 1874) ${ }^{+}$ & & & & 4 & & & 5 & 1 & & 10 \\
\hline Zelotes scrutatus (O. P.-Cambridge, 1872) & 17 & 32 & 6 & 16 & 15 & & 1 & & & 87 \\
\hline Zelotes segrex (Simon, 1878) & & 24 & & 13 & & & & & & 37 \\
\hline Zelotes solstitialis Levy, 1998 & & 13 & & 51 & 13 & & & & & 77 \\
\hline Zelotes subterraneus (C.L. Koch, 1833) & & 57 & 14 & 2 & 42 & & & & & 115 \\
\hline Zelotes tenuis (L. Koch, 1866) & 2 & 22 & & 4 & 1 & 1 & & & & 30 \\
\hline Total & 103 & 321 & 226 & 300 & 171 & 26 & 134 & 19 & 22 & 1322 \\
\hline
\end{tabular}

